\title{
Educação sexual na perspectiva histórico-cultural
}

\section{Sexual education in a historical cultural perspective}

\author{
Nilson Dinis* \\ Araci Asinelli-Luz**
}

\begin{abstract}
RESUMO
O tema da sexualidade tornou-se obrigatório nos Parâmetros Curriculares Nacionais do Brasil, devendo ser tratado como um tema transversal. Assim, a sexualidade não é mais um tema exclusivo das aulas de Biologia, mas deve ser trabalhada em todas as disciplinas do currículo por uma visão culturalista. Essa mudança de paradigma implica discutir todos os aspectos da sexualidade, inclusive as novas identidades sexuais e de gênero. Isso exige que o tema seja discutido nos cursos de formação docente, preparando o/a educador/a para resistir a discursos normativos sobre corpo, gênero e sexualidade.

Palavras-chave: sexualidade; gênero; educação sexual; formação docente.
\end{abstract}

\begin{abstract}
The theme of sexuality became obligatory in the National Curriculum Parameters in Brazil, and it must be dealt with as a transversal theme. This way, sexuality is not an exclusive theme of Biology's classes anymore, but must be taught in all the disciplines of the curriculum by means of a

* Professor adjunto do Setor de Educação e do Programa de Pós-Graduação em Educação da Universidade Federal do Paraná. E-mail: ndinis@ufpr.br

** Professora adjunta do Setor de Educação e do Programa de Pós-Graduação em Educação da Universidade Federal do Paraná. E-mail: asinelli@ufpr.br
\end{abstract}


culturalist vision. This turning of paradigm implies the discussion of all the aspects of sexuality, even the new sexual and gender identities. This demands that the theme has to be debated in teacher training courses, preparing the educator to resist to normative discourses about body, gender and sexuality.

Key-words: sexuality; gender; sexual education; teacher training.

Entre as inúmeras justificativas apontadas pelos Parâmetros Curriculares Nacionais (PCNs) ao abordar a importância do tema transversal da "orientação sexual" no currículo escolar está o fato de que:

A partir de meados dos anos 1980, a demanda por trabalhos na área da sexualidade nas escolas aumentou devido à preocupação dos educadores com o grande crescimento da gravidez indesejada entre os adolescentes e com o risco da contaminação por HIV (vírus da Aids) entre os jovens. A princípio, acreditava-se que as famílias apresentavam resistência à abordagem dessas questões no âmbito escolar, mas atualmente sabe-se que os pais reivindicam orientação sexual nas escolas, pois reconhecem não só a sua importância para crianças e jovens, como também a dificuldade de falar abertamente sobre esse assunto em casa (BRASIL, 1997, p. 111).

A cada dia, os discursos da mídia e os discursos da educação nos trazem novos dados alarmistas sobre o aumento do índice de "gravidez precoce" ou de "gravidez indesejada" entre as adolescentes, em consonância com a justificativa apontada pelos Parâmetros Curriculares Nacionais. Um desses índices alarmantes e moralizantes é questionado por Dimenstein (2002, p. 62), ao apontar uma pesquisa divulgada pela Casa Branca, nos Estados Unidos, concluindo que "a gravidez de adolescentes custa anualmente US\$ 1 bilhão aos norte-americanos apenas para construir novas prisões". O discurso aponta para uma maior tendência de criminosos saírem da barriga de jovens mães solteiras, culpando a desestruturação familiar como uma de suas causas. Além dos custos com a construção de novos presídios, contabilizam-se entres os prejuízos as despesas com o benefício social fornecido pelo governo às grávidas e a perda na produtividade da economia, pois a adolescente no período de gravidez estaria fora do mercado de trabalho. 
O relatório denominado Situação da População Mundial, do Fundo de População das Nações Unidas (UNFPA, 2003), também informa que cerca de 14 milhões de mulheres entre 15 e 19 anos têm filhos a cada ano, sendo a mortalidade materna a principal causa de morte entre mulheres nesta faixa etária, além da vulnerabilidade à Aids. Salienta que, na América Latina, além da possibilidade do aborto, o casamento precoce e a gravidez na adolescência têm conseqüências graves na educação das adolescentes, em muitos casos levando ao abandono da escola.

Prevenção à Aids, às DSTs (doenças sexualmente transmissíveis), bem como o aumento dos índices de gravidez na adolescência, têm sido as principais justificativas normatizantes utilizadas pelo discurso educacional para desenvolver programas de educação sexual. Os termos gravidez precoce e gravidez indesejada, este último presente no próprio texto dos PCNs, têm sido vistos com freqüência no discurso da educação. Mas alguns/mas autores/as têm justamente criticado o uso dos termos gravidez precoce, gravidez indesejada ou não planejada, preferindo utilizar a expressão gravidez na adolescência. Segundo Castro et al. (2004, p. 134):

\begin{abstract}
Medos, inseguranças, baixa auto-estima, assimetrias de gênero nas negociações sobre direitos sexuais e reprodutivos podem derivar em uma gravidez, quer para mulheres jovens quer para adultas, inclusive como forma compensatória. Aliás, é interessante notar que se acentua o caráter de não planejada, não desejada, para as gravidezes ocorridas entre jovens, sem se fazer referência que tal tipo de gravidez possa ocorrer também para mulheres adultas.
\end{abstract}

Discursos normativos sobre a sexualidade, a gravidez, os modos de ser homem ou de ser mulher, de ser adulto/a, ou de ser jovem e adolescente, de ser mãe e de ser pai, percorrem os espaços da escola e da mídia. Na modernidade, a mídia torna-se um elemento de formação cultural com igual e, às vezes, até maior presença do que a formação escolar, o que faz, muitas vezes, com que um discurso afete o outro. É assim que muitos dos discursos construídos pela mídia ajudam a formar também as representações da escola e da família sobre a sexualidade e a adolescência. Nessa perspectiva, Henry Giroux (1996) nos apresenta uma interessante análise sobre o filme Kids, dirigido por Larry Clark, que, no final da década de 1990, aterrorizou muitos/as educadores/as e famílias ao apresentar uma imagem conservadora ideológica da juventude 
como sendo despida de capacidade crítica, exercendo uma sexualidade e uma agressividade fora de controle, produzindo o que o autor chama de "uma política de demonização da juventude", justificando intervenções educativas e normativas por parte dos adultos. Soares retoma o tema, resumindo alguns dos principais enunciados desse discurso:

As teses científicas sobre a juventude enfatizam que, a partir de transformações corporais e do desenvolvimento dos hormônios sexuais, o corpo na adolescência está à mercê de impulsos de difícil controle. Então, nessa perspectiva, o planejamento e a premeditação estão descartados da relação sexual. O que permite ao jovem ingressar na vida sexual parece ser o acaso e o impulso do momento. O adolescente é habitado, por um lado, por um novo corpo; por outro, por um estatuto social que o subestima e que o declara incapaz. Assim, a adolescência é uma questão de poder que os adultos devem administrar; e os adolescentes devem ser protegidos deles mesmos. É evidente que o corpo e a sexualidade são enfatizados em outros momentos da vida, mas na adolescência há um excesso desse realce (SoAres, 2000, p. 155).

Entender a sexualidade em uma perspectiva histórico-cultural, e não mais em uma perspectiva estritamente biológica, tem sido o principal fundamento dessas críticas. E aqui não podemos deixar de ressaltar a contribuição dos estudos de Michel Foucault. Foucault (1988) critica a hipótese repressiva sobre a sexualidade que agiria principalmente pela negação da sexualidade e de seu silenciamento. Ela não explica, por exemplo, a proliferação de discursos sobre a sexualidade que vivemos hoje com a constante exposição do tema na mídia e as confissões da vida sexual produzidas pelos ícones midiáticos (atores/atrizes e modelos) que estão expostas na internet, nos programas de TV e nas revistas voltadas ao público adolescente. Para Foucault, na modernidade desenvolveram-se outras técnicas de controle sobre a sexualidade que não passam mais pelo seu silenciamento, mas justamente pela sua confissão, pela incitação ao discurso da sexualidade, pela sua visibilidade:

Em todo caso, a hipótese de um poder de repressão que nossa sociedade exerceria sobre o sexo e por motivos econômicos revela-se insuficiente se for preciso considerar toda uma série de reforços e de intensificações 
que uma primeira abordagem manifesta: proliferação de discursos, e discursos cuidadosamente inscritos em exigências de poder; solidificação do despropósito sexual e constituição de dispositivos suscetíveis não somente de isolá-lo, mas de solicitá-lo, suscitá-lo, constituí-lo em foco de atenção, de discurso e de prazeres; produção forçosa de confissão e, a partir dela, instauração de um sistema de saber legítimo e de uma economia de prazeres múltiplos. Muito mais do que um mecanismo negativo de exclusão ou de rejeição, trata-se da colocação em funcionamento de uma rede sutil de discursos, saberes, prazeres e poderes; não se trata de um movimento obstinado em afastar o sexo selvagem para alguma região obscura e inacessível, mas, pelo contrário, de processos que o disseminam na superfície das coisas e dos corpos, que o excitam, manifestam-no, fazem-no falar, implantam-no no real e lhe ordenam dizer a verdade: todo um cintilar visível do sexual refletido na multiciplicidade dos discursos, na obstinação dos poderes e na conjugação do saber com o prazer (FouCAULT, 1988, p. 70-71).

O sexo torna-se objeto de saber por meio de dispositivos de poder nos discursos sobre a sexualidade presentes, por exemplo, no discurso médicocientífico que busca a normatização da sexualidade, com especial atenção sobre a sexualidade da mulher, da criança, do/a adolescente, e das chamadas sexualidades periféricas, como a homossexualidade, que até 1990 ainda era diagnosticada pelo discurso médico no Brasil como perversão ou distúrbio sexual, embora, a partir de 1985, já não constasse mais nos manuais da Associação Médica Brasileira como tal. Em 17 de maio de 1990, a Organização Mundial de Saúde (OMS), entendendo que a homossexualidade não é um distúrbio, a retirou de seus manuais de doença. É importante lembrar também que a Resolução do Conselho Federal de Psicologia $n^{\circ} 1 / 99$, de 23 de março de 1999, estabelece normas de atuação para os psicólogos em relação à questão da orientação sexual, "considerando que a homossexualidade não constitui doença, nem distúrbio e nem perversão". Destacamos o Art. 3º em que se afirma que "os psicólogos não exercerão qualquer ação que favoreça a patologização de comportamentos ou práticas homoeróticas, nem adotarão ação coercitiva tendente a orientar homossexuais para tratamentos não solicitados" (CEPAC, 2006, p. 62)

No entanto, apesar de alguns avanços, elementos de uma cultura repressiva parecem ainda sobreviver nos discursos religiosos ou familiares que se posicionam contra a perspectiva de uma educação sexual nas escolas. Mas, se os mecanismos repressivos são os mais evidentes, a partir de Foucault, apren- 
demos também a ficar atentos para outros discursos, pretensamente liberadores da sexualidade, que são atravessados por mecanismos sutis e sofisticados de normatização e controle sobre a sexualidade. Fischer (1996, p. 170) analisa, por exemplo, como o "discurso da sexualidade adolescente agora incorpora expressões novas - 'momento certo', 'pessoa certa'-, termos sem definição precisa, que falam de um retorno a valores carregados de conservadorismo, como a virgindade e o romantismo das relações". Esse mesmo discurso passa pela mídia, pela escola, pela família e pelas aulas de educação sexual. Parece óbvio que, na visão de educadoras/es e da família conservadora, esse "momento certo" pode ser prorrogado até os limites de um "quanto mais tarde melhor", produzindo novas formas de controle sobre a sexualidade adolescente.

Esses discursos normativos também atravessam os programas de educação sexual nas escolas. Eles estão presentes, por exemplo, nos PCNs, ao abordarem o tema da orientação sexual. Uma primeira divergência já apontamos no tocante ao próprio uso do termo "orientação sexual". Preferimos utilizar o termo para se referir ao direcionamento do afeto no exercício da sexualidade em relação a outro sujeito. É assim que falamos, por exemplo, em uma orientação sexual homossexual, heterossexual ou bissexual, caso o desejo sexual se direcione, respectivamente, a alguém do mesmo sexo, do sexo oposto ou de ambos os sexos. Nesse sentido, não cabe à educação "orientar" a sexualidade, pois a orientação sexual do sujeito é uma construção histórico-cultural, resultado de suas vivências singulares, que devem ser respeitadas pela escola. Já sobre as possíveis intervenções da educação na sexualidade, preferimos o termo educação sexual. Um trabalho de educação sexual significa problematizar a sexualidade, não no sentido de encará-la como problema a ser resolvido, mas de questionar as evidências, apresentar um leque de conhecimentos para que a sexualidade seja compreendida com um aspecto predominantemente histórico-cultural, e para que os discursos normativos que regem as construções de nossas imagens do masculino e do feminino, bem como as diversas imagens de ter prazer com o próprio corpo e/ ou com o corpo do/a outro/a sejam desconstruídos, permitindo novas vivências acerca da sexualidade.

Certamente os PCNs representam alguma conquista, já que os primeiros programas de educação sexual abordavam o tema de uma perspectiva exclusivamente biologizante, com aulas sobre anatomia e fisiologia dos sistemas reprodutores (a reprodução era um dos imperativos da sexualidade) e sobre a prevenção da "gravidez precoce" e das doenças sexualmente transmissíveis. O próprio termo sistema reprodutor vinculava a sexualidade necessariamente à reprodução, e não à produção de prazer. Já os PCNs ressaltam que o tema deve ser abordado a partir de três principais eixos: o corpo como matriz da 
sexualidade, relações de gênero e prevenção às doenças sexualmente transmissíveis/Aids. Assim, o tradicional tópico de prevenção às doenças sexualmente transmissíveis continua, graças a sua importância, mas enfatiza-se também a necessidade de "discutir a discriminação social e o preconceito de que são vítimas os portadores do HIV e os doentes de Aids, por intermédio dos direitos de cidadania e da proposição da adoção de valores como a solidariedade, o respeito ao outro e a participação de todos no combate aos preconceitos." (BRASIL, 1997, p. 147).

Discutir o corpo como matriz da sexualidade também não é, segundo os PCNs, uma discussão simplesmente anatômico-fisiológica, como costumava ocorrer nas aulas tradicionais de Ciências, pois:

[...] corpo é concebido como um todo integrado, de sistemas interligados e inclui emoções, sentimentos, sensações de prazer/desprazer, assim como as transformações nele ocorridas ao longo do tempo. Há que se considerar, portanto, os fatores culturais que intervêm na construção da percepção do corpo, este todo que inclui as dimensões biológica, psicológica e social (BRASIL, 1997, p. 139-140).

Propõe-se também a discussão da matriz "relações de gênero", enfatizando o caráter histórico-cultural de nossas formas de ser homem ou ser mulher. A inclusão do tema relações de gênero nos PCNs "tem como objetivo combater relações autoritárias, questionar a rigidez dos padrões de conduta estabelecidos para homens e mulheres e apontar para sua transformação" (BRASIL, 1997, p. 144). No entanto, apesar desses avanços, Altmann (2001) aponta uma série de críticas ao texto dos PCNs. Para a autora, a orientação sexual nos PCNs é entendida como sendo de caráter informativo, e a sexualidade é entendida como um "dado da natureza", "algo inerente" e "necessário", falando-se, às vezes, em "necessidade básica", contrastando com uma perspectiva históricocultural sobre a sexualidade:

Há, nestes trechos, indicativos normalizadores da sexualidade. Ela é vista sob o ponto de vista biológico, atrelada às funções hormonais. Quanto à experimentação erótica, à curiosidade e ao desejo, estes são considerados comuns, quando a dois. A potencialidade erótica do corpo a partir da puberdade é concebida como centrada na região genital, 
enquanto à infância só é admitido um caráter exploratório pré-genital. Os conteúdos devem favorecer a compreensão de que o ato sexual, bem como as carícias genitais, só tem pertinência quando manifestado entre jovens e adultos (Altmann, 2001, p. 581).

Em outros momentos dos PCNs são mencionados aspectos históricos da sexualidade, mas, como ressalta ainda Altmann (2001, p. 581): “esta dimensão histórica é pensada como sendo construída em cima de algo naturalmente dado. Em outras palavras, a sexualidade e o sujeito são pensados como essências sob as quais há um investimento da cultura".

Como aponta Dinis (2006), minorias sexuais e de gênero também são tema ausente nos PCNs. Nos objetivos da proposta, menciona-se apenas o respeito à "diversidade de valores, crenças e comportamentos existentes e relativos à sexualidade, desde que seja garantida a dignidade do ser humano" (BRASIL, 1997, p. 133). Ou ainda, "reconhecer como determinações culturais as características socialmente atribuídas ao masculino e ao feminino, posicionando-se contra discriminações a eles associadas" (BRASIL, 1997). Sem uma referência explícita ao tema da discriminação contra homossexuais e outras diversidades sexuais (como travestis, transexuais, bissexuais, etc.) no espaço escolar, resta ao/à educador/a apenas a interpretação da necessidade ou não da inclusão do tema a partir da leitura dos objetivos, já que é possível interpretálos apenas como a necessidade de questionar as representações sociais acerca do masculino e do feminino, sem mencionar outras práticas sexuais que sejam divergentes da norma heterossexual.

A dificuldade em compreender todos os aspectos implicados quando pensamos a sexualidade como sendo produzida na dimensão histórico-cultural também tem sido observada nas demandas realizadas por professores/as ou por discentes, nos cursos de formação ou de aperfeiçoamento dos quais participamos. Uma demanda bastante comum nesses grupos é "aprender a lidar com a sexualidade", assim como aparecem outras demandas na educação como "aprender a lidar com a/o adolescente" ou "aprender a lidar com a criança com necessidades educativas especiais". Nesse sentido, é interessante observarmos a carga semântica negativa da palavra "lidar", que no dicionário Aurélio (FERREIRA, 1986, p. 1030) está associada a sentidos como "lutar", "sofrer", "sustentar", "pelejar" e "labutar". Mesmo quando aparentemente utilizamos a palavra em um sentido afirmativo, por exemplo, "lidar com a vida", na afirmação está implícito não o lidar com as alegrias da vida, mas justamente com os infortúnios.

Propomos a inversão do termo "lidar com" para proposições afirmativas 
como "trabalhar com" ou "viver com". Entendemos que não se aprende a lidar com a sexualidade, assim como não se aprende a lidar com necessidades educativas especiais, ou com crianças e adolescentes. Somos seres histórico-culturais e a construção de nossas identidades se dá desde o momento de nosso nascimento, na relação com as diferenças. Nesse sentido, também não nos tornamos socializados, já nascemos socializados, já que desde os primeiros momentos de nossas vidas estamos interagindo com a/o outra/o, representada/o, geralmente, nessa primeira fase, pela figura materna. Portanto, trabalhar com a sexualidade, ou com a diferença, ou com as necessidades educativas especiais, não são experiências que vamos construir exclusivamente na escola, são experiências que já aprendemos no momento em que estamos inseridos em uma sociedade. Elas fazem parte da dimensão do humano, à qual pertencemos, portanto, obrigatoriamente, convivemos com elas, já que somos sujeitos histórico-culturais que constroem suas identidades na relação com o/a outro/a.

Como ressaltam Asinelli-Luz, Morales e Manikowski (2007), a prática da educação sexual na escola reflete como o/a educador/a percebe, vivencia e representa a sua própria sexualidade. Estudo realizado com profissionais das áreas de educação e saúde vinculadas ao Programa Saúde e Prevenção nas Escolas, dos Ministérios da Educação e da Saúde, em diferentes municípios brasileiros, mostra que temas como aborto, preconceito, orientação sexual, exploração sexual e violência sexual, por exemplo, raramente são trabalhados na escola, assim como há pouco aproveitamento do espaço escolar para a discussão e conhecimento por parte dos/as estudantes e professoras/es sobre o Estatuto da Criança e do Adolescente. Ainda, segunda as autoras, da mesma forma, discussões sobre o uso de preservativo (masculino e feminino), a prevenção do HIV e Aids, a gravidez na adolescência, sem a devida discussão e reflexão sobre a maternidade e paternidade responsável, podem ajudar na manutenção de uma representação de sexualidade que domestica e medicaliza os corpos.

Entender a sexualidade de uma perspectiva histórico-cultural, como fator de aprendizagem e interação social, significa superar os limites impostos pela educação escolar. A possibilidade de vivenciar a diversidade das relações afetivas e sociais provocada pela educação sexual contribui para a compreensão e uma experimentação de novas possibilidades do exercício da alteridade em contextos mais amplos que os familiares, e é dessa forma que "o indivíduo se humaniza quando a cultura impregna a biologia, e um novo ser, assim redefinido, se eleva como pessoa" (BrasiL, 1994, p. 11). E essa deve ser, por fim, a principal justificativa para que o tema seja discutido e trabalhado na escola e nos cursos de formação docente. 


\section{REFERÊNCIAS}

ALTMANN, H. Orientação sexual nos Parâmetros Curriculares Nacionais. Revista Estudos Feministas, Florianópolis, v. 2, n. 9, p. 575-585, jul./dez. 2001.

ASINELLI-LUZ, A.; MORALES, C.; MANIKOWSKI, T. S. Educação sexual: perfil e prática de educadores/as. In: MOSTRA SAÚDE E PREVENÇÃO NAS ESCOLAS, 2. Brasília: UnB, 2007.

BRASIL. Ministério da Educação e do Desporto. Secretaria de Projetos Educacionais Especiais. Diretrizes para uma política educacional de sexualidade. Brasília: MEC/ Sepespe, 1994. Série Educação Preventiva Integral. v. 1.

BRASIL. Secretaria de Educação Fundamental. Parâmetros curriculares nacionais: pluralidade cultural, orientação sexual. Brasília: MEC/SEF, 1997.

CASTRO, M. G.; ABRAMOVAY, M.; SILVA, L. B. Juventudes e sexualidade. Brasília: Unesco Brasil, 2004.

CEPAC. Centro Paranaense de Cidadania. Guia para educadores(as). Educando para a diversidade: como discutir homossexualidade na escola? Curitiba: Ciranda, 2006.

CHILAND, C. O sexo conduz o mundo. Rio de Janeiro: Companhia de Freud, 2005.

DIMENSTEIN, G. Aprendiz do futuro: cidadania hoje e amanhã. São Paulo: Ática, 2002.

DINIS, N. F. Educação, cidadania e as minorias sexuais e de gênero. In: SCHMIDT, M. A.; STOLTZ, T. (Orgs.). Educação, cidadania e inclusão social. Curitiba: Aos Quatro Ventos, 2006. p. 130-135.

FERREIRA, A. B. H. Novo dicionário da língua portuguesa. Rio de Janeiro: Nova Fronteira, 1986.

FISCHER, R. M. B. Adolescência em discurso: mídia e produção de subjetividade. Tese (Doutorado em Educação) - Universidade Federal do Rio Grande do Sul, Porto Alegre, 1996.

FOUCAULT, M. História da sexualidade I: a vontade de saber. Rio de Janeiro: Graal, 1988.

GIROUX, H. A. O filme Kids e a política de demonização da juventude. Educação \& Realidade, Porto Alegre, v. 1, n. 21, p. 123-136, jan./jun. 1996. 
MARGULIS, L.; SAGAN D. O que é sexo? Rio de Janeiro: Zahar, 2002.

SOARES, R. Adolescência: monstruosidade cultural? Educação \& Realidade, Porto Alegre, v. 2, n. 25, p. 151-159, jul./dez. 2000.

UNFPA. The state of world population 2003: making 1 billion count: investing in adolescents' health and rights. London: UNFPA, ONU, 2003. Disponível em: $<$ http:// unfpa.org/swp/2003/English/ch1/index.htm>. Acesso em: 24/4/2007.

Texto recebido em 24 mar. 2006 Texto aprovado em 10 set. 2006 
